\title{
Evidence for Enhanced Neurobehavioral Vulnerability to Nicotine during Periadolescence in Rats
}

\author{
Walter Adriani, ${ }^{1}$ Sabine Spijker, ${ }^{2}$ Véronique Deroche-Gamonet, ${ }^{1}$ Giovanni Laviola, ${ }^{3}$ Michel Le Moal, ${ }^{1}$ August B. Smit, ${ }^{2}$ \\ and Pier Vincenzo Piazza ${ }^{1}$ \\ Institut National de la Santé et de la Recherche Médicale U588, Université “V. Segalen”, Bordeaux 2, Domaine de Carreire, 33077 Bordeaux, France, \\ ${ }^{2}$ Department of Molecular and Cellular Neurobiology, Institute of Neurosciences, Faculty of Earth and Life Sciences, Vrije Universiteit, 1081 HV \\ Amsterdam, The Netherlands, and ${ }^{3}$ Section of Behavioral Pathophysiology, Laboratory di Fisiopatologia di Organo e di Sistema, Istituto Superiore di Sanita, \\ 00161 Rome, Italy
}

\begin{abstract}
Epidemiological studies indicate that there is an increased likelihood for the development of nicotine addiction when cigarette smoking starts early during adolescence. These observations suggest that adolescence could be a "critical" ontogenetic period, during which drugs of abuse have distinct effects responsible for the development of dependence later in life. We compared the long-term behavioral and molecular effects of repeated nicotine treatment during either periadolescence or postadolescence in rats. It was found that exposure to nicotine during periadolescence, but not a similar exposure in the postadolescent period, increased the intravenous self-administration of nicotine and the expression of distinct subunits of the ligand-gated acetylcholine receptor in adult animals. Both these changes indicated an increased sensitivity to the addictive properties of nicotine. In conclusion, adolescence seems to be a critical developmental period, characterized by enhanced neurobehavioral vulnerability to nicotine.
\end{abstract}

Key words: nicotine; adolescence; intravenous; self-administration; acetylcholine receptor; PCR

\section{Introduction}

Several epidemiological studies indicate that there is an increased likelihood for the development of nicotine addiction when cigarette smoking starts early during adolescence (Taioli and Wynder, 1991; Breslau and Peterson, 1996; Kandel and Chen, 2000). These observations suggest that adolescence could represent a "critical" ontogenetic period. During adolescence, drugs of abuse may have distinct effects, not yet fully characterized, which may be responsible for an increased risk to develop drug dependence later in life.

In rodents, periadolescence has been classically defined as the ontogenetic period that encompasses the $7-10 \mathrm{~d}$ preceding the onset of puberty (at $\sim 40 \mathrm{~d}$ of age) and the first few days thereafter (Spear and Brake, 1983). This developmental period is characterized by specific neurobiological and behavioral features (Stamford, 1989; Teicher et al., 1995; Laviola et al., 1999; Trauth et al., 1999, 2001; Spear, 2000). The validity of such an animal model for the purpose of comparison or extrapolation to the human case has been recently confirmed (Spear, 2000). Compared with adults, periadolescent rodents show an unbalanced spontaneous behavior, consisting of increased novelty seeking, decreased novelty-induced stress and anxiety, as well as elevated levels of

\footnotetext{
Received Dec. 5, 2002; revised March 5, 2003; accepted March 6, 2003.

This work was supported by the Institut National de la Santé et de la Recherche Médicale, the University Victor Segalen-Bordeaux 2, the Institut Fédératif de Recherche $n^{\circ} 8$, a Marie Curie Fellowship (W.A.), and Grant MW 903-42-048 (S.S.) from Nederlands Wetenschappelijk Onderzoek.

Correspondence should be addressed to Pier Vincenzo Piazza, Institut National de la Santé et de la Recherche Médicale U588, Domaine de Carreire, Rue C. Saint-Saëns, 33077 Bordeaux, France. E-mail: pier-vincenzo. piazza@bordeaux.inserm.fr.

W. Adriani's present address: Section of Behavioral Pathophysiology, Laboratory di Fisiopatologia di Organo e di Sistema, Istituto Superiore di Sanita, 00161 Rome, Italy.

Copyright $\odot 2003$ Society for Neuroscience $\quad$ 0270-6474/03/234712-05\$15.00/0
}

impulsivity and restlessness (Laviola et al., 1999, 2003). As for psychopharmacological features, after repeated psychostimulant administration, periadolescent rodents exhibit a greater locomotor sensitization and a less marked place conditioning (Laviola et al., 1995; Tirelli et al., 2003). Interestingly, they also show a higher vulnerability to nicotine-induced changes in dopaminergic and cholinergic functions (Trauth et al., 1999, 2001).

The aim of the present study was to assess whether the magnitude of the long-term effects of nicotine would differ depending on the age of previous drug exposure. For this purpose, we compared the self-administration (SA) of nicotine and the expression of different subunits of the ligand-gated acetylcholine receptors (nAChRs) in adult rats that had been exposed to the same regimen of nicotine administration during either periadolescence or postadolescence.

The nAChRs were studied because the addictive properties of nicotine (Stolerman and Shoaib, 1991) are thought to be mediated by activation of the nAChRs (Picciotto et al., 1995) expressed in the ventral tegmental area (VTA), which induces an increase in dopamine (DA) release from mesencephalic DA neurons (Pontieri et al., 1996). Gene expression was measured in tissue samples of the ventral midbrain containing mainly the VTA but also a small portion of the most medial part of the substantia nigra $(\mathrm{SN})$. These brain regions contain GABA neurons in addition to DA neurons. Both types of neurons express two major forms of the nAChRs (Klink et al., 2001): (1) a homopentamer formed by five $\alpha 7$ subunits, and (2) a heteropentamer formed by a combination of $\alpha$ and $\beta$ subunits, with $\alpha 4$ and $\beta 2$ being the predominant ones. The most predominant nAChRs in GABA neurons is the $\alpha 4(3)-\beta 2(2)$ type. The nAChRs expressed in DA neurons, in addition to $\alpha 4$ and $\beta 2$, also contain $\alpha 5$ and/or $\alpha 6$ subunits (Klink et al., 2001). 


\section{Materials and Methods}

Subjects. Sprague Dawley rats (Iffa Credo, St. Germain sur l'Arbresle, France) were housed with a $12 \mathrm{hr}$ light/dark cycle (lights off at 1:30 P.M.). Temperature $\left(22 \pm 1^{\circ} \mathrm{C}\right)$ and humidity $(60 \pm 5 \%)$ were controlled. Animals had ad libitum access to food and water throughout the experiment. Breeding pairs were formed for 2 weeks, after which the male was removed, and the females were housed individually. The day of delivery was considered as postnatal day $0(\mathrm{P} 0)$. On $\mathrm{P} 1$, litters were culled to four males and four females. On P21, rat pups were weaned. Only male subjects were used for the present experiments, and each of the four experimental groups contained one individual per litter. Delivery of animals within the periadolescent group was planned to occur $25 \mathrm{~d}$ after the one of animals within the postadolescent group. This schedule allowed starting the nicotine and vehicle treatments at the same time in both age groups.

Surgery. A SILASTIC catheter (internal diameter, $0.28 \mathrm{~mm}$; external diameter, $0.61 \mathrm{~mm}$; dead volume, $12 \mu \mathrm{l}$ ) was implanted in the jugular vein (Caine et al., 1993; Deroche et al., 1999) under ketamine $(100 \mathrm{mg} / \mathrm{kg}$, i.p.) (Imalgene; Merial, Lyon, France)-xylazine ( $4 \mathrm{mg} / \mathrm{kg}$, i.p.) (Rompun $2 \%$; Bayer, Leverkusen, Germany) anesthesia. The proximal end was placed in the right atrium while the distal end was passed under the skin and fixed in the midscapular region. Rats were allowed to recover for 5-7 $\mathrm{d}$ after surgery. During the first $4 \mathrm{~d}$ after surgery, rats received an antibiotic treatment [gentamycin, $1 \mathrm{mg} / \mathrm{kg}$, i.v. (gentalline $80 \mathrm{mg}$; ScheringPlough, Levallois-Perret, France)]. After surgery, catheters were flushed daily with a saline solution containing unfractionated heparin (100 IU/ ml) (héparine choay; Sanofi Winthrop, Gentilly, France).

Evaluation of nicotine SA. The intravenous SA setup (Imetronic, Pessac, France) consisted of 16 SA chambers made of Plexiglas and metal. Each chamber $(40$-cm-long $\times 30$-cm-wide $\times 52$-cm-high) was located within a larger exterior opaque box equipped with exhaust fans that assured air renewal and masked background noise. Briefly, animals were placed in a SA chamber where their chronically implanted intravenous catheter was connected to a pump-driven syringe (infusion speed, 20 $\mu 1 / \mathrm{sec}$ ). Two holes, located in opposite sides of the SA chamber at $5 \mathrm{~cm}$ from the grid floor, were used as devices to record responding. A cue light $(1.8 \mathrm{~cm}$ in diameter) was located $10.5 \mathrm{~cm}$ above one hole.

Daily SA sessions were conducted during the first half of the dark phase for $1 \mathrm{hr}$. Introduction of the animal's nose into one hole (active device) turned on a cue light located above it and then, 1 sec later, switched on the infusion pump. The cue light remained on for a total of $4 \mathrm{sec}$. Each infusion was followed by a $20 \mathrm{sec}$ time out period during which further responses in the active hole had no scheduled consequences. Nose pokes in the other hole (inactive device) never had scheduled consequences. The self-infusion volume was $20 \mu \mathrm{l}$ and contained $0.04 \mathrm{mg} / \mathrm{kg}$ of nicotine. A fixed ratio (FR; number of nose pokes necessary to obtain one infusion of nicotine) was used within each session but was progressively increased across sessions according to the following progression: FR1, 6 d; FR2, FR3, FR5, 3 d each; FR8, FR10, FR15, FR20, FR25, FR30, 4 d each. This across sessions progressive ratio (PR) schedule has been described as a useful tool to study motivational effects of drugs (Risner and Goldberg, 1983; Risner and Cone, 1986; Piazza et al., 2000). In particular, across-sessions PR schedules, as compared with more widely used withinsession schedules, have the advantages to avoid confounding within-session satiation with cessation in consumption caused by increased ratio response requirements (Giordano et al., 2001). Experimental contingencies were controlled, and data was collected with a Windows-compatible personal computer software (Imetronic, Pessac, France).

Evaluation of locomotor activity. The locomotor activity setup (Imetronic) consisted of 12 Plexiglas boxes (30-cm-long, 40-cm-high, and 30-cm-wide). Each box was equipped with two computer-monitored photocell beams separated by $14 \mathrm{~cm}$. Locomotion was estimated by the number of cage crossings, i.e., consecutive breaks of the two beams. The test was performed under dim illumination $1 \mathrm{hr}$ and $30 \mathrm{~min}$ after the dark phase started. Animals were placed in the cages immediately after intraperitoneal nicotine injection, and locomotor activity was monitored for $15 \mathrm{~min}$.

Evaluation of $n A C h R$ gene expression. Animals were killed by decapita- tion, and their brains were dissected. Samples of the ventral midbrain, containing mainly the VTA but also a small portion of the most medial part of the $\mathrm{SN}$, were isolated and stored at $-80^{\circ} \mathrm{C}$ until RNA isolation. Quantitative PCR was used to evaluate the expression of genes coding for different nAChR subunits. From each rat, total RNA was isolated (Chomczynski and Sacchi, 1987) $(\sim 30 \mu \mathrm{g})$, and from 50\% total RNA, mRNA was isolated using magnetic beads (Dynal, Great Neck, NY). cDNA was synthesized using hexanucleotide primers and used in quantitative PCR (ABI 7700) according to the manufacturer's protocol (Perkin-Elmer). Gene-specific primers were designed using Primer Express (Perkin-Elmer): Hypoxanthine guanine phosphoribosyltransferase (HPRT; M63983) sense: 5'-ATGGGAGGCCATCACATTGT-3', antisense: 5' -ATGTAATCCAGCAGGTCAGCAA- $3^{\prime} ; \alpha 2$ subunit sense: $5^{\prime}$-CATCCCAGGCTAGCGAGATTC- ${ }^{\prime}$, antisense: $5^{\prime}$-TCAGACGGTCAGCAATGTAGTGT-3'; $\alpha 3$ subunit sense: $5^{\prime}$ CCATGGTGATTGATCGCATCT-3' , antisense: $5^{\prime}$-GCCATCAAGGGTTGCAGAA-3'; $\alpha 4$ subunit sense: 5'-GAAGGCGTCCAGTACATTGCA-3', antisense: $5^{\prime}$-GGCCACGTATTTCCAGTCCTC-3'; $\alpha 5$ subunit sense: $5^{\prime}$ GCTGGATACGGTGCCTCATAC-3', antisense: 5'-CCAGGCTGACCAACAACTCAC-3'; $\alpha 6$ subunit sense: $5^{\prime}$-CAAGTGAGATAGCACCTGGCAAG-3', antisense: $5^{\prime}$-CATCAGGTGGGTGCTCTGAA- ${ }^{\prime}$; $\alpha 7$ subunit sense: $5^{\prime}$-ATGTGCAAGAGTGCCTTCGTG-3', antisense: $5^{\prime}$-CCTGATTGGTCGCTTACCCAT-3'; $\beta 2$ subunit sense: $5^{\prime}$-CAGTACTGGGTGCAAGATGGATC-3', antisense: $5^{\prime}$-AGGCTGGAGGACTATGTGTGAAC$3^{\prime}$; $\beta 3$ subunit sense: $5^{\prime}$-TGCAGGGCACTGAGAGAATG-3', antisense: $5^{\prime}$-CGTCTCCAAATTGCCCAACT- $3^{\prime}$; $\beta 4$ subunit sense: $5^{\prime}$-CACCAGCACCTTGCCCATA-3', antisense: 5'-TGGGTCCCAAGCTCTGGAG-3'. The efficiency of amplification of each primer set was tested and used only if $\sim 2$. Measurements were performed in duplicate.

Protocol. 96 animals were administered intraperitoneally with either nicotine $(0.4 \mathrm{mg} / \mathrm{kg} ; n=48)$ or vehicle $(0.9 \%$ saline solution; $n=48)$ once per day for $10 \mathrm{~d}$. The periadolescent group was treated from P34 to $\mathrm{P} 43$. The postadolescent group received an identical treatment between P60 and P69. This period was chosen because it is intermediate between periadolescence and P75, the age that is used for most studies in adult rats. Five weeks later, i.e., at an age when both groups were adults, animals were used either for nicotine SA, evaluation of nAChR gene expression, or evaluation of nicotine-induced locomotor activity.

Thirty-two littermates were used for nicotine SA [16 nicotine pretreated ( $n=8$ for each age group) and 16 vehicle pretreated ( $n=8$ for each age group)]. Sixteen littermates were used for evaluation of $\mathrm{nAChR}$ gene expression [ 8 nicotine pretreated ( $n=4$ for each age group) and 8 vehicle pretreated ( $n=4$ for each age group)]. In a supplementary experiment, 48 littermates [ 24 nicotine pretreated $(n=12$ for each age group) and 24 vehicle pretreated ( $n=12$ for each age group)] were treated either with saline or nicotine following an identical schedule. This time, after a 5 week drug-free period, they received an intraperitoneal injection of nicotine and were tested for the locomotor response to the drug. In each experimental group, half of the animals were tested with 0.3 $\mathrm{mg} / \mathrm{kg}$ of nicotine, whereas the other half was tested with $0.6 \mathrm{mg} / \mathrm{kg}$ of nicotine. This experiment was aimed to control for a potential difference in locomotor sensitization between the periadolescent and postadolescent groups that could account for the observed differences in SA behavior.

Statistical analyses. For behavioral studies, all data were analyzed using ANOVA. For acquisition of nicotine SA, active and inactive responses during the first $15 \mathrm{~d}$ (up to FR5) were used as dependent variables. For the PR study, the number of active nose pokes during the last $2 \mathrm{~d}$ at each FR were used as the dependent variable. For nicotine-induced locomotor activity, total activity over the $15 \mathrm{~min}$ of the test was used as the dependent variable. Age of pretreatment (periadolescent-postadolescent) and treatment (vehicle-nicotine pretreatment) were used as between-subject factors. Time (number of sessions or number of ratios) and hole (activeinactive) were used as within-subject factors.

For gene expression, cycle threshold values were used to calculate differences in expression levels after correction for tissue input by the HPRT control. Student's $t$ tests were performed to analyze the statistical differences. 


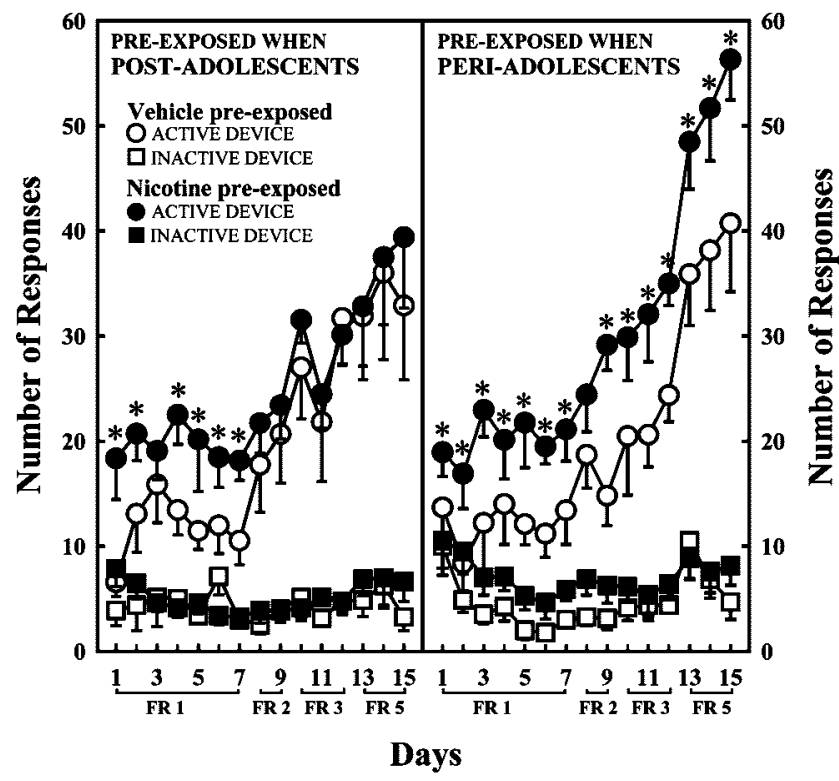

Figure 1. Animals pre-exposed to nicotine during periadolescence (right panel) and postadolescence (left panel) differed during acquisition of nicotine SA (age $\times$ treatment $X$ day interaction, $\left.F_{(14,350)}=1.80 ; p<0.05\right)$. Within the periadolescent group, nicotine-pretreated animals showed more nose pokes in the active device delivering nicotine $(0.04 \mathrm{mg} / \mathrm{kg}$ per infusion) than did vehicle-pretreated controls, and this during the entire acquisition period (treatment effect, $\left.F_{(1,11)}=4.64 ; p<0.05\right)$. Conversely, within the postadolescent group, nicotine-pretreated animals showed more active nose pokes than vehicle-pretreated controls, only during the FR1 period (treatment $\times$ day $\times$ hole interaction, $F_{(14,196)}=2.03 ; p<0.05$ ). The two groups did not differ anymore when the FR requirement was increased over days. The two vehicle-pretreated groups did not differ at any time (age effect, $F_{(1,12)}=2.28 ; p=0.6$ ). Responses in the inactive device had no schedule consequences and were used as a control of SA. The two age groups (periadolescent and postadolescent) did not differ for the number of inactive responses. Similarly, in both age groups, vehicle-treated and nicotine-pretreated animals did not differ for inactive responses. FR indicates the number of active responses necessary to obtain one infusion of nicotine. ${ }^{*} p<0.05$ in comparison with corresponding vehiclepretreated animals.

\section{Results}

\section{Nicotine SA}

Three animals were excluded from the study because of catheter failure (one in the periadolescent nicotine-pretreated group and two in the periadolescent vehicle-pretreated group).

Pretreatment with nicotine during periadolescence, but not during postadolescence, increased nicotine SA in adult subjects. Thus, when compared with animals that received a pretreatment with vehicle, adult animals pretreated with nicotine during periadolescence showed an increased number of responses for the drug during the whole acquisition period (Fig. 1). These animals also showed increased motivation to self-administer nicotine, in that they showed a higher rate of responding for the drug over a broader range of ratios than did animals pretreated with nicotine during the postadolescent period (Fig. 2). The latter group, compared with vehicle-pretreated controls, showed a transient increase in responding that was only observed during the first few days of SA corresponding to the lowest ratio requirement (Fig. 1, FR1). After this period, animals pretreated with nicotine during the postadolescent period never differed from vehicle-pretreated controls (Figs. 1, 2). Differences in nicotine SA between periadolescent and postadolescent pretreated rats could not rely on differences in age of testing ( 11 and 15 weeks, respectively) because periadolescent and postadolescent vehicle-pretreated animals did not differ for nicotine SA. Similarly, differences in SA between nicotine-pretreated periadolescent and postadolescent rats

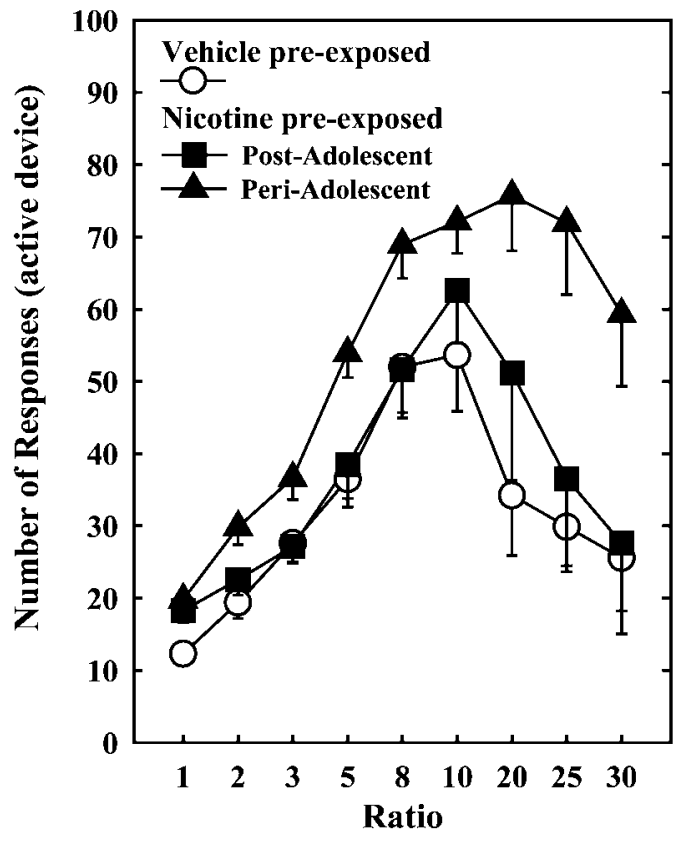

Figure 2. Animals pre-exposed to nicotine during periadolescence and postadolescence differed during a between session PR schedule for nicotine SA. FR indicates the number of responses necessary to obtain one infusion of nicotine. Because animals pretreated with vehicle during either periadolescence or postadolescence did not differ $\left(F_{(1,12)}=2.28 ; p>0.60\right)$, they were collapsed in the vehicle group. In the postadolescent group, the number of responses in the active device delivering nicotine $(0.04 \mathrm{mg} / \mathrm{kg}$ per infusion) did not differ between animals pretreated with nicotine and animals pretreated with vehicle, with the exception of FR1 (Fig. 1). In these two groups, responses increased regularly up to FR10 and progressively decreased at FR20, 25, and 30, providing the typical bell-shaped curve observed with this PR schedule. In animals pretreated with nicotine during periadolescence, no significant decrease in response was observed up to FR30, these animals showing a higher number of active responses than the other two groups at FR20, 25, and $30(p<0.05)$.

do not seem to depend on differences in the locomotor stimulant effects of nicotine. Indeed, animals receiving an identical nicotine pretreatment during either periadolescence or postadolescence did not differ for the locomotor response to nicotine when tested 5 weeks later. Both groups showed a sensitized response to acute nicotine, when compared with the vehicle-pretreated animals (treatment effect, $\left.F_{(1,52)}=10.4 ; p<0.005\right)$, but no age-related differences were evidenced (treatment $X$ age interaction, $\left.F_{(1,52)}=0.0004 ; p=0.98\right)$. Whatever the dose tested, the two nicotine-pretreated groups showed a similar nicotine-induced activation, independently from age of pretreatment [age effect, $F_{(1,13)}=0.074 ; p=0.78$ for $0.3 \mathrm{mg} / \mathrm{kg} ; F_{(1,13)}=0.51 ; p=0.48$ for $0.6 \mathrm{mg} / \mathrm{kg}$; data not shown).

\section{nAchR gene expression}

In adult subjects pretreated with nicotine during periadolescence, an increase in gene expression of the DA neuron-specific subunits ( $\alpha 5$ and $\alpha 6$ ) and of the $\beta 2$ subunit was found. In contrast, no significant changes were found in the transcript levels of the other $\alpha$ subunits (Fig. 3). Moreover, a significant upregulation of the $\beta 3$ subunit was found in animals receiving nicotine during both postadolescence and periadolescence. Finally, mRNA levels for the $\alpha 2$ and $\beta 4$ subunits were not reliably detected.

\section{Discussion}

Taken together, the results of the acquisition experiment and of the PR schedule indicate that animals pretreated with nicotine 


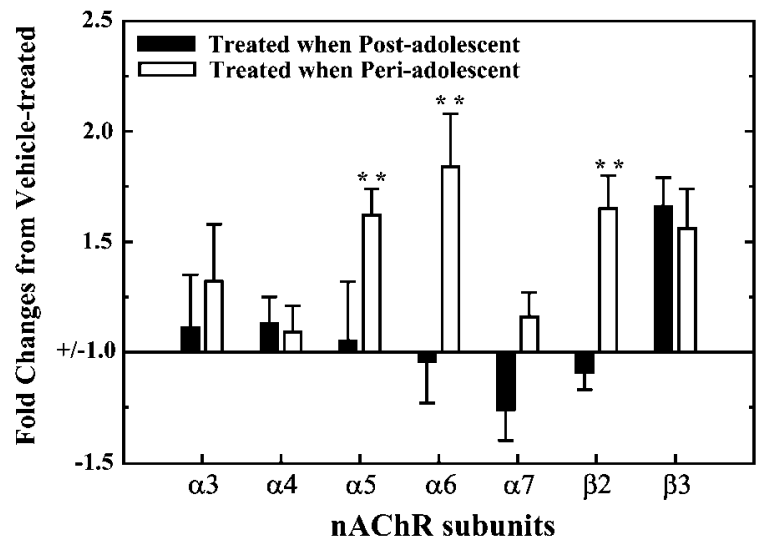

Figure 3. Animals pre-exposed to nicotine during periadolescence and postadolescence differed for transcript levels of different subunits of the $n A C h R s$ in the ventral midbrain. Results are expressed as fold changes from the matched vehicle-pretreated controls. An upregulation of the $\alpha 5, \alpha 6$, and $\beta 2$ subunits was found in animals pretreated with nicotine during periadolescence. In contrast, no significant changes were found in animals that received the same nicotine pretreatment but during postadolescence, with the exception of the $\beta 3$ subunit that was similarly increased in both groups. ${ }^{* *} p<0.001$ in comparison with animals pretreated during postadolescence.

during periadolescence become more sensitive to the reinforcing effects of this drug. Thus, a higher drug intake during acquisition and a higher performance in a PR schedule have been associated with a higher reinforcing efficacy of the drug (Piazza et al., 2000).

The increase in the motivational properties of drugs after their repeated administration is a phenomenon, defined sensitization, that is considered to be one of the major processes leading to addiction (Robinson and Berridge, 1993). Indeed, it has been repeatedly shown that, in adult animals, pre-exposure to various drugs of abuse, and in particular to psychostimulants like amphetamine and cocaine, facilitates the acquisition of SA and increases the motivational performance in PR schedules of reinforcement (Piazza et al., 1990; Pierre and Vezina, 1997; Schenck and Partridge, 1997). So far, nicotine was an exception in this respect. Namely, pretreatment with this drug during adulthood induced only a transient facilitation of SA behavior (Shoaib et al., 1997), very similar to the one that we describe here for postadolescent rats. Interestingly, our data demonstrate that nicotine can actually induce a clear-cut sensitization in a manner that is similar to other drugs of abuse, but only if it is administered during periadolescence.

These behavioral effects of nicotine, which are so highly specific to the adolescent period, were also associated with very specific changes in transcript levels of nAChR subunits. In adult subjects pretreated with nicotine during periadolescence, an increase in gene expression of the $\alpha 5, \alpha 6$, and $\beta 2$ subunits was found. Probably, this increase occurred specifically in DA neurons, because they are the only cell type-expressing receptors that include the $\alpha 5$ and/or $\alpha 6$ subunits (Klink et al., 2001). These changes, if they were translated in an increase in protein levels, might have contributed to an increased vulnerability to nicotine in the periadolescent group. Indeed, a deletion of the $\beta 2$ subunit in $\beta 2-1-$ mice abolishes both nicotine-induced DA release and nicotine SA (Picciotto et al., 1995; Lena and Changeux, 1999). Hence, the upregulation of mRNA for the $\beta 2$ subunit may suggest relatively higher levels of the heteropentameric receptors, which in turn may explain the increased reinforcing effects of nicotine.

The upregulation of mRNAs coding for the $\alpha 5$ and the $\alpha 6$ subunits suggest that the heteropentameric nAChRs were upregulated and/or became more sensitive to nicotine. Indeed, the incorporation of an $\alpha 5$ subunit into $\alpha 3 \beta 2$ receptors leads to a 50-fold increase in sensitivity to nicotine (Gerzanich et al., 1998; Nelson and Lindstrom, 1999; Kuryatov et al., 2000). Similarly, the inclusion of an $\alpha 6$ subunit into $\alpha 3 \beta 2$ receptors renders the heteropentamer less responsive to acetylcholine (the endogenous ligand), but increases the potency and efficacy of nicotine, i.e., it turns nicotine into a full agonist instead of a partial agonist (Kuryatov et al., 2000). On this line, it has been shown that blockade of $\alpha 6$ subunit expression, through injections of antisense oligonucleotides in the VTA, blocks the stimulant effects of nicotine (Le Novere et al., 1999). All these evidences support the hypothesis that an enhanced sensitivity to the reinforcing effects of nicotine may follow an increase in $\alpha 5$ and $\alpha 6$ subunit transcript levels.

A significant upregulation of the $\beta 3$ subunit was found in animals receiving nicotine during both postadolescence and periadolescence. Little is known about the functional role of this subunit. However, its selective increase does not seem to be accompanied by major changes in nicotine SA, as observed in the postadolescent group. Finally, our study agrees with observations showing that $\alpha 2$ and $\beta 4$ subunits are not expressed in the ventral midbrain (Klink et al., 2001) because we could not reliably detect mRNA levels for these subunits.

The results of the present experiments suggest that periadolescence is a critical developmental period, during which exposure to nicotine induces behavioral and molecular changes that are strikingly different from those observed in subjects exposed to the same drug but later in life. Furthermore, these distinct molecular changes seem compatible with an increased sensitivity to the addictive effects of nicotine. The mechanisms by which nicotine can have differential effects on the postadolescent and the periadolescent brain cannot be precisely defined at this stage and certainly deserve further investigations. However, different levels of maturation of the CNS, and consequently different sensitivity of the genome to external stimuli are probably implicated.

Indeed, studies on the adolescent brain have shown that active cell replication and remodeling of synapses occur prominently during this period (Spear, 2000). DA and noradrenergic systems show large changes in neurotransmitter levels and activity during adolescence (Loizou, 1972; Segawa, 2000). In particular, a reduced basal rate of DA release and a reduced pool of readily releasable DA have been reported in periadolescent rats (Stamford, 1989). Also, DA receptors and nAChRs are overexpressed in rat brain throughout adolescence, because they undergo programmed pruning thereafter (Naeff et al., 1992; Teicher et al., 1995; Andersen et al., 1997). Finally, and consistent with our data, it has been recently shown that the long-term consequences of a nicotine pretreatment are more marked and persistent with adolescent than with adult exposure (Trauth et al., 1999, 2001).

In conclusion, adolescence seems to be a critical developmental period, characterized by a neurobehavioral vulnerability to nicotine. Specifically, nicotine exposure during adolescence may render an individual more vulnerable to its addictive properties. Recently, an increased vulnerability to nicotine consumption has been also shown during early adolescence in mice (Adriani et al., 2002). Consequently, the analysis of the mechanisms rendering the adolescent brain so vulnerable to nicotine in particular and to drugs of abuse in general could open new avenues for the understanding of drug dependence. 


\section{References}

Adriani W, Macri S, Pacifici R, Laviola G (2002) Peculiar vulnerability to nicotine oral self-administration in mice during early adolescence. Neuropsychopharmacology 27:212-224.

Andersen SL, Rutstein M, Benzo JM, Hostetter JC, Teicher MH (1997) Sex differences in dopamine receptor over-production and elimination. NeuroReport 8:1495-1498.

Breslau N, Peterson EL (1996) Smoking cessation in young adults: age at initiation of cigarette smoking and other suspected influences. Am J Public Health 86:214-220.

Caine SB, Lintz R, Koob GF (1993) Intravenous drug self-administration techniques in animals. In: Behavioural neuroscience: a practical approach (Sahgal A, ed), pp 117-143. Oxford: Oxford University.

Chomczynski P, Sacchi N (1987) Single-step method of RNA isolation by acid guanidinium thiocyanate-phenol-chloroform extraction. Anal Biochem 162:156-159.

Deroche V, Le Moal M, Piazza PV (1999) Cocaine self-administration increases the incentive motivational properties of the drug in rats. Eur J Neurosci 11:2731-2736.

Gerzanich V, Wang F, Kuryatov A, Lindstrom J (1998) Alpha 5 subunit alters desensitization, pharmacology, $\mathrm{Ca}++$ permeability and $\mathrm{Ca}++$ modulation of human neuronal alpha 3 nicotinic receptors. J Pharmacol Exp Ther 286:311-320.

Giordano LA, Bickel WK, Shahan TA, Badger GJ (2001) Behavioral economics of human drug self-administration: progressive ratio versus random sequences of response requirements. Behav Pharmacol 12:343-347.

Kandel DB, Chen K (2000) Extent of smoking and nicotine dependence in the United States: 1991-1993. Nicotine Tob Res 2:263-274.

Klink R, de Kerchove d'Exaerde A, Zoli M, Changeux JP (2001) Molecular and physiological diversity of nicotinic acetylcholine receptors in the midbrain dopaminergic nuclei. J Neurosci 21:1452-1463.

Kuryatov A, Olale F, Cooper J, Choi C, Lindstrom J (2000) Human alpha6 AChR subtypes: subunit composition, assembly, and pharmacological responses. Neuropharmacology 39:2570-2590.

Laviola G, Wood RD, Kuhn C, Francis R, Spear LP (1995) Cocaine sensitization in periadolescent and adult rats. J Pharmacol Exp Ther 275:345-357.

Laviola G, Adriani W, Terranova ML, Gerra G (1999) Psychobiological risk factors for vulnerability to psychostimulants in human adolescents and animal models. Neurosci Biobehav Rev 23:993-1010.

Laviola G, Macri S, Morley-Fletcher S, Adriani W (2003) Risk-taking behavior in adolescent mice: psychobiological determinants and early epigenetic influence. Neurosci Biobehav Rev 27:19-31.

Lena C, Changeux JP (1999) The role of beta 2-subunit-containing nicotinic acetylcholine receptors in the brain explored with a mutant mouse. Ann NY Acad Sci 868:611-616.

Le Novere N, Zoli M, Lena C, Ferrari R, Picciotto MR, Merlo-Pich E, Changeux JP (1999) Involvement of alpha6 nicotinic receptor subunit in nicotine-elicited locomotion, demonstrated by in vivo antisense oligonucleotide infusion. NeuroReport 10:2497-2501.

Loizou LA (1972) The postnatal ontogeny of monoamine-containing neurons in the central nervous system of the albino rat. Brain Res 40:395-418.

Naeff B, Schlumpf M, Lichtensteiger W (1992) Pre- and post-natal development of high affinity $\left[{ }^{3} \mathrm{H}\right]$ nicotine binding sites in rat brain regions: an autoradiographic study. Dev Brain Res 68:163-174.

Nelson ME, Lindstrom J (1999) Single channel properties of human alpha3
AChRs: impact of beta2, beta4 and alpha5 subunits. J Physiol (Lond) 516:657-678.

Piazza PV, Deminiere JM, le Moal M, Simon H (1990) Stress- and pharmacologically-induced behavioral sensitization increases vulnerability to acquisition of amphetamine self-administration. Brain Res 514:22-26.

Piazza PV, Deroche-Gamonent V, Rouge-Pont F, Le Moal M (2000) Vertical shifts in self-administration dose-response functions predict a drugvulnerable phenotype predisposed to addiction. J Neurosci 20:4226-4232.

Picciotto MR, Zoli M, Lena C, Bessis A, Lallemand Y, LeNovere N, Vincent P, Pich EM, Brulet P, Changeux JP (1995) Abnormal avoidance learning in mice lacking functional high-affinity nicotine receptor in the brain. Nature 374:65-67.

Pierre PJ, Vezina P (1997) Predisposition to self-administer amphetamine: the contribution of response to novelty and prior exposure to the drug. Psychopharmacology 129:277-284.

Pontieri FE, Tanda G, Orzi F, Di Chiara G (1996) Effects of nicotine on the nucleus accumbens and similarity to those of addictive drugs. Nature 382:255-257.

Risner ME, Cone EJ (1986) Intravenous self-administration of fencamfamine and cocaine by beagle dogs under fixed-ratio and progressive-ratio schedules of reinforcement. Drug Alcohol Depend 17:93-102.

Risner ME, Goldberg SR (1983) A comparison of nicotine and cocaine selfadministration in the dog: fixed-ratio and progressive-ratio schedules of intravenous drug infusion. J Pharmacol Exp Ther 224:319-326.

Robinson TE, Berridge KC (1993) The neural basis of drug craving: an incentive-sensitization theory of addiction. Brain Res Rev 18:247-291.

Schenck S, Partridge B (1997) Sensitization and tolerance in psychostimulant self-administration. Pharmacol Biochem Behav 57:543-550.

Segawa M (2000) Development of the nigrostriatal dopamine neuron and the pathways in the basal ganglia. Brain Dev [Suppl 1]22:S1-S4.

Shoaib M, Schindler CW, Goldberg SR (1997) Nicotine self-administration in rats: strain and nicotine pre-exposure effects on acquisition. Psychopharmacology 129:35-43.

Spear LP (2000) The adolescent brain and age-related behavioral manifestations. Neurosci Biobehav Rev 24:417-463.

Spear LP, Brake SC (1983) Periadolescence: age-dependent behavior and psychopharmacological responsivity in rats. Dev Psychobiol 16:83-109.

Stamford JA (1989) Development and ageing of the rat nigrostriatal dopamine system studied with fast cyclic voltammetry. J Neurochem 52:1582-1589.

Stolerman IP, Shoaib M (1991) The neurobiology of tobacco addiction. Trends Pharmacol Sci 12:467-473.

Taioli E, Wynder EL (1991) Effect of the age at which smoking begins on frequency of smoking in adulthood. N Engl J Med 325:968-969.

Teicher MH, Andersen SL, Hostetter JC (1995) Evidence for dopamine receptor pruning between adolescence and adulthood in striatum but not nucleus accumbens. Dev Brain Res 89:167-172.

Tirelli E, Laviola G, Adriani W (2003) Ontogenesis of behavioral sensitization and conditioned place preference induced by psychostimulants in laboratory rodents. Neurosci Biobehav Rev 27:163-178.

Trauth JA, Seidler FJ, McCook EC, Slotkin TA (1999) Adolescent nicotine exposure causes persistent upregulation of nicotinic cholinergic receptors in rat brain regions. Brain Res 851:9-19.

Trauth JA, Seidler FJ, Ali SF, Slotkin TA (2001) Adolescent nicotine exposure produces immediate and long-term changes in CNS noradrenergic and dopaminergic function. Brain Res 892:269-280. 